\title{
S1-2. Investigating teaching practices that promote learning in science lessons
}

\author{
Eduardo F Mortimer \\ Faculdade de Educação da Universidade Federal de Minas Gerais
}

\begin{abstract}
In this talk we use the notion of communicative approach, as outlined in our book (Mortimer \& Scott 2003), as a way of highlighting the science teaching practices carried out by two teachers, one Brazilian and th e other British. The characteristics that emerge from these practices demonstrate that teaching for meaningful learning involves progressive shifting between authoritative and dialogic communicative approaches. On the one hand, dialogic discourse is open to different points of view. The discourse direction changes as ideas are introduced and explored and the teachers assume a neutral position, avoiding evaluative comments and encouraging and probing student ideas. On the other hand, authoritative discourse focuses on a single perspective, normally the school science view. The discourse direction is prescribed in advance and the authority of teacher is clear: he/she acts as a gatekeeper to points of view, through reshaping, ignoring, rejecting student ideas. The relationship between dialogic and authoritative approaches is that dialogic exploration of both everyday and scientific views requires resolution through authoritative guidance by the teacher. In shifting between dialogic and authoritative discourses these two teachers shows a number of pedagogical skills: they sustain a line of speech and thought, through which ideas are introduced, reviewed and consolidated in a cumulative process involving the creation of temporal links. They also monitor and follow the students' understanding. They systematically progress from the phenomenon to the description and explanation. And they select carefully developed activities to ensure the advancement of the scientific story. They also show affective and emotional skills, systematically encouraging the participation of all members of the class, offering approval, modeling the enthusiasm, recalling individual ideas and arguments of the students and linking to their names, and being consistent, warm and having control.
\end{abstract}

With our analytical framework we are able to highlight all these features and to get a more precise idea of what are good teaching practices.

Mortimer, E.F. \& Scott, P. (2003) Meaning Making in Secondary Science Classroom. Maidenhead: Open University Press. 